ISSN: $2146-3042$

DOI: $10.25095 /$ mufad.606024

\title{
Davranışsal Denetim: Finansal Tablo Hilelerin Hüristik Bir Yaklaşımla İncelenmesi*
}

Murat ATİK**

\section{ÖZET}

Insan beyni rassal (tesadüf) sayı üretimini kendi zihninde oluşturduğu belli sistematik kurallara göre gerçekleştirmektedir. Bir kişi rassal bir sayı ürettiğinde sayıları tesadüfi olarak seçtiğini dü̧̈ünse de aslında sayı üretimi rassal olarak değil kendi zihnindeki mental hesaplama işlemi sonucundaki belli bir sistematik kurala göre yapılmaktadır. Bu çalışma ile insanların zihinsel süreçlerinde rassal sayı üretiminde sistematik kuralların neler olduğu, hangi örüntüleri kullandıkları ve sayıları algılama biçimlerinin ortaya çıkartılması amaçlanmaktadır. Insan beyninin rassal saylları algllama ve üretme biçimleri belirlendikten sonra kurdukları örüntülerden yola çıkarak finansal tablolarda üretilen sayıların tesadüfi mi oluştuğu yoksa finansal tabloları hazırlayanlar tarafindan belli bir kurala göre mi oluşturulduğu tespit edilerek, finansal tablolardaki hilelerin tespit edilmesinde kullanılabileceği öngörülmektedir. Bu kapsamda 177 kişiye oluşturulan senaryo verilerek, senaryolara uygun rassal sayı üretmeleri istenmiştir. Yapılan analizler sonucunda deneklerin rassal sayıları, varsayıma uygun olarak belli bir sistematik kurala göre oluşturdukları görülmüştür. Analizler sonucunda tespit edilen örüntülerin finansal tablolarda kullanılması ile yapılan hileleri ortaya çıkarmada kullanılabilecek bir denetim aracı haline gelebilecĕgi değerlendirilmektedir.

Anahtar Kelimeler: Davranışsal Denetim, Mental Muhasebe, Rassal Sayı, Hüristik, Benford Yasası.

JEL Sinıflandırması: M40, M41, M42.

\section{Behavioral Auditing: Investigation Of Fraud In Financial Statements With A Heuristic Approach \\ ABSTRACT}

The human brain creates random numbers according to certain systematic rules it creates in its own mind. Although one thinks that he randomly chose numbers when he produces a random number, in fact, production of numbers depends on certain systematic rule as a result of mental calculation process in his own mind rather than performed randomly. This study aimed to reveal the systematic rules in the production of random numbers in individuals' mental processes, what patterns they use and how they perceive numbers. It is foreseen that if the numbers of the human brain detecting and producing the random numbers are determined based on the patterns they have formed, the numbers generated in the financial statements are either incidental or if the financial statements are prepared according to a certain rule and it can be used to identify the tricks in the financial statements. In this context, 177 participants tried to produce a random number according to the scenarios by stratified sample. As a result of the analyzes, it was observed that the subjects formed the random numbers according to a certain systematic rule in accordance with the hypothesis. As a result of the analyzes, it can be considered as an audit tool that can be used to reveal the tricks in the financial statements.

Keywords: Behavioral Auditing, Mental Accounting, Random Number, Heuristic, Benford's Law.

Jel Classification: M40, M41, M42.

Makale Gönderim Tarihi: 01.06.2019

Makale Kabul Tarihi: 01.08.2019

Makale Türü: Araştırma Makalesi

\footnotetext{
* Bu çalışma, 1-4 Mayıs 2019 tarihlerinde Bursa'da düzenlenen V. Uluslararası Muhasebe ve Finans Sempozyumu'nda özet bildiri olarak sunulmuştur.

** Assist Prof., Milli Savunma Üniversitesi, matik@kho.edu.tr, ORCID:0000-0002-5150-0203.
} 


\section{GíRiş}

Teknolojinin gelişmesiyle birlikte geleneksel denetim yöntemleri de değişikliğe uğrayarak artan ölçüde teknolojiye bağımlı hale gelmiştir. Geleneksel denetim yöntemlerini kullanarak hile ve usulsüzlükleri tespit etmek giderek zorlaşmaktadır. Çünkü bilgi teknolojilerindeki gelişmelerle birlikte verilerinin çok büyük miktarlara ulaşması ve bu dijital veri yığınları arasında olabilecek hile ve usulsüzlükleri tespit etmek veya proaktif denetim anlayışı ile önlemeye çalışmak denetimi zorlaştırmaktadır.

Denetim şirketlerinin hile ve usulsüzlüklerin tespitinde uyguladığı standart prosedürler artık yeterli olamamaya başlamıştır. Teknolojinin hızla ilerlemesi klasik denetim yöntemlerine yardımcı farklı dijital denetim tekniklerinin geliştirilmesini sağlamıştır. Özellikle büyük veri yığınlarını analiz ederek bu veri kümelerindeki anomalileri, kaymaları ve diğer olan dışı faaliyetleri tespit edebilecek denetim yöntemlerinin geliştirilmesi yapılan denetimin daha sağlıklı olmasını ve kırmızı bayrakların tespit edilmesini sağlayabilecektir. Hilede ana unsur insandır. İnsanların hileli işlemleri yaparken sayıları nasıl ürettiği ve kullandığının tespit edilmesi durumunda söz konusu saptamaların denetimde kullanılabilecek bir araç haline getirilmesi de mümkün olabilecektir.

$\mathrm{Bu}$ çalışmada, insan beyninin rassal sayı üretirken kullandığı sistematikleri ve örüntüleri tespit ederek denetimde kullanılabilir bir araç haline getirilmesi amaçlanmaktadır. Çalışmanın birinci bölümünde hile ile ilgili temel kavram anlatılmıştır. İkinci bölümde hile türleri, hile denetimi, hile tarafları açıklandıktan sonra üçüncü bölümde hile denetimini önleyici yöntemler üzerinde durulmuştur. Dördüncü bölümde çalışmanın amacını oluşturan bilişsel düzeyde insan beyninin rassal sayı üretiminin sistematiği açıklanmaya çalışılmıştır. Sistematik örüntüler belirlendikten sonra finansal tablo denetiminde nasıl kullanılacağına ilişkin bir değerlendirme yapılmıştır.

\section{HILE KAVRAMI VE TÜRLERI}

\subsection{Hile Kavramı}

Hile, belli bir amaç doğrultusunda işlem, kayıt ve belgelerin bilinçli olarak tahrip edilmesi olarak tanımlanmaktadır (Çatıkkaş, 2011:19; Yıldız ve Baskan, 2014:2). Hatada bilgisizlik ve dikkatsizlik varken hile de bilerek ve kasten yapılma durumu söz konusudur. Hile bilinçli bir şekilde yapıldığı için kendiliğinden ortaya çıkması beklenmemekte ve tespit edilmesi de son derece güç olmaktadır (Christensen vd., 2005:70). 82 no'lu SAS (Statement of Auditing Standards) raporunda, Mali Tablo Denetiminde sahteciliğin değerlendirilmesinde ve denetçilerin hileli işlemlere ilişkin sorumluluklarını yerine getirmek için ne yapmaları gerektiğine dair bir ölçüt oluşturulmuştur.

Hilenin tek bir şeklinin olmaması ve insan zekasının sürekli yeni yöntem ve usuller geliştirilmesi denetimin daha dinamik ve güncel gelişmeleri takip etmesini zorunlu k1lmaktadır. ACFE'nin (Association of Certified Fraud Examiners) 125 ülke ve 2690 hile olayını inceleyerek hazırladığı 2018 raporunda hile türlerini 3 gruba ayırmıştır. Bunlar varlıkların kötüye kullanılması, yolsuzluk (Corruption) ve finansal tablo hileleridir. Söz konusu bu üç hile türünün gerçekleşme oranları ve tutarları Tablo 1'dedir. 
Tablo 1. Hile türleri ve İşletmelere Olan Maliyetleri

\begin{tabular}{|l|c|c|}
\hline Hile Türü & Olay \% & $\begin{array}{c}\text { Yol Açtığ1 } \\
\text { Maliyet } \\
\text { (Medyan) }\end{array}$ \\
\hline Varlıkların Kötüye Kullanılması & $\% 89$ & $111.000 \$$ \\
\hline Yolsuzluk & $\% 38$ & $250.000 \$$ \\
\hline Finansal Tablo Hileleri & $\% 10$ & $800.000 \$$ \\
\hline
\end{tabular}

Kaynak: ACFE Report (2018:10)

Tablo 1'e göre en fazla yapılan hile türü \%89 ile işletme varlıklarının kötüye kullanımıdır. Ancak çarpıcı olan nokta varlıkların kötüye kullanımı her ne kadar en yaygın hile türü olarak gözükse de işletmeye maliyeti diğer hile türlerine göre daha düşük seviyededir. Finansal tablo hileleri \%10 ile en az yapılmasına karşın işletmeye en ağır maliyete $(800.000 \$)$ yol açan hile türüdür. Hileli işlemlerin işletmelere verdikleri zararların yüzdesel gösterimi Şekil 1'dedir.

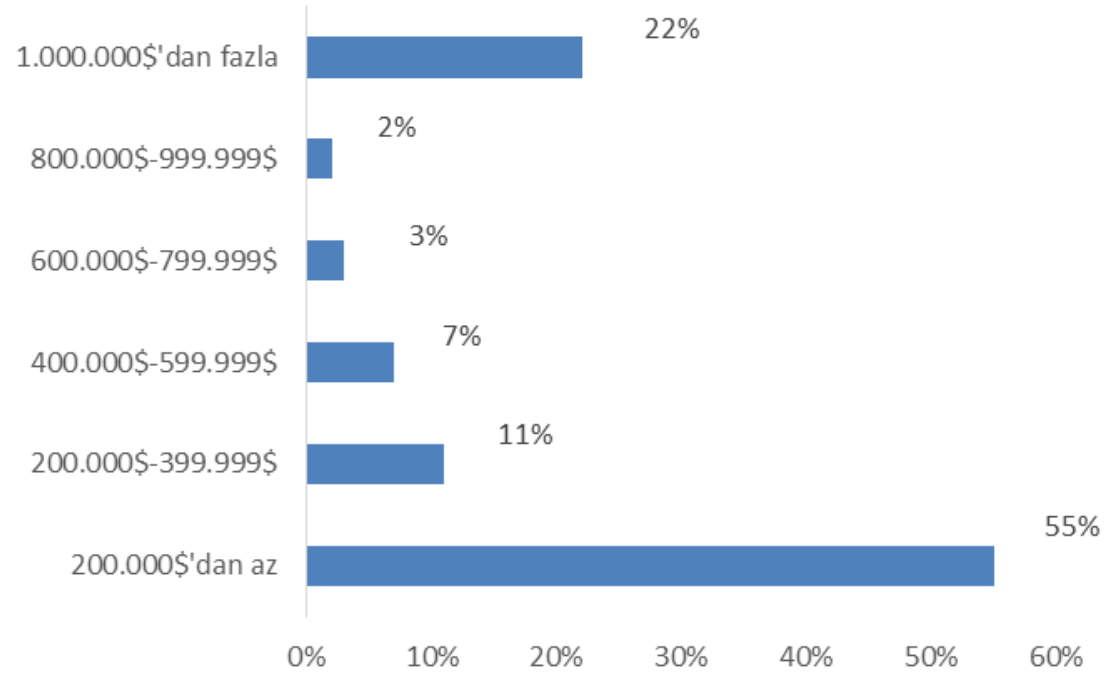

Kaynak: ACFE Report (2018:9)

Şekil 1. Hile İşlemlerin Yol Açtığı Maliyetler (\%)

ACFE'nin Şekil 1'de gösterilen raporuna göre hileli bir işlem ortaya çıktığında \%55'i bir işletmede en az 200.000\$lik bir maliyete sebep olurken \%22'si de yaklaşık 1.000.000\$' dan daha fazla bir maliyete yol açmaktadır. 




Kaynak: ACFE Report (2018:17)

Şekil 2. Hile İşlemlerin Ortaya Çıkış Şekilleri (\%)

Şekil 2'de hileli işlemlerin ortaya çıkış şekilleri gösterilmektedir. Çalışanların ihbarı ve firma sahipleri firma içi ihbar kaynaklarını temsil ederken, müşteri şikayetleri, tedarikçi ve rakiplerin ihbarları ise, firma dışı ihbar kaynaklarını göstermektedir (Terzi ve Şen, 2015: 481). Hileli işlemlerin ortaya çıkışının \%53'ü çalışanların ihbarıyla, \%21 müşterilerin şikayetleriyle ve \%14'de isimsiz ihbarlar sonucunda gerçekleşmiştir. Hileli işlemlerin ancak \%2'si ise firma sahipleri tarafından ortaya çıkartılmıştır. Her ne kadar işletme sahipleri kontrolün kendilerinde olduğunu düşünseler de aslında durumun hiç böyle olmadığı, risk altında bulundukları ve aslında hiç bir şeyden haberdar olmadıkları anlaşılmaktadır.

\subsection{Hile Elması}

Donald Gressey tarafindan geliştirilen Hile Teorisine göre, hile üçgeni olarak gösterilen bask1, firsat ve haklı gösterme unsurlarının varlığı durumunda hileli bir durumun gerçekleşme olasılı̆̆ının olabileceği ifade edilmektedir. SAS No:99 standardına göre hileli bir durumun oluşabilmesi için hile üçgenindeki sadece bir unsurun varlığının bile hileli işlemler için yeterli olabileceğini savunmaktadır (Ertekin, 2017:75). 


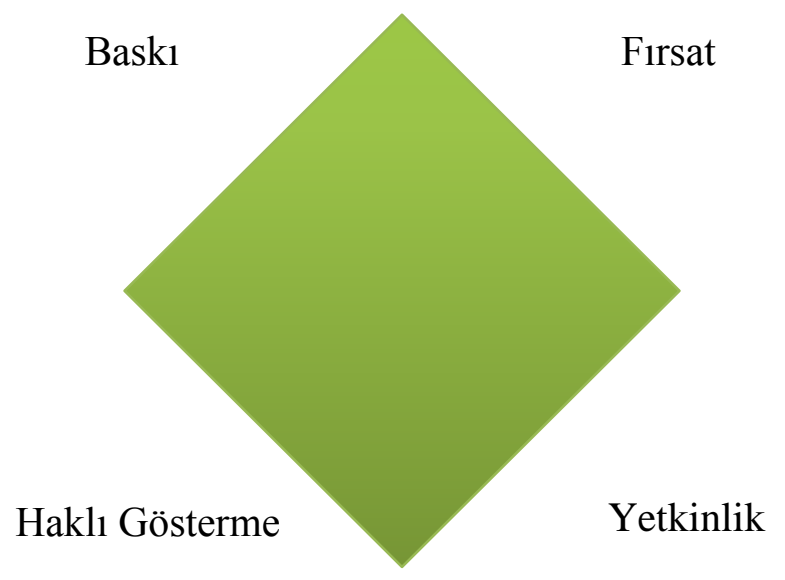

Kaynak: Wolfe ve Hermanson (2004:38)

Şekil 3. Hile Elmasının Unsurları

Hile üçgenindeki baskı unsuru çalışanlar üzerindeki çeşitli sebeplerle ortaya çıkan baskıları temsil etmektedir. Bu baskılara örnek yöneticilerin koydukları gerçekçi olmayan hedefler ve çalışanların kişisel mali sıkıntı içinde olmaları gösterilmektedir. Fırsat unsuru, hileli bir işlemin yapılmasına firsat verecek bir ortamın olmasıdır. İşletmenin sağlıklı bir iç kontrol yapısının olmaması hileli işlemlerin doğmasına sebep olabilecektir. Haklı gösterme ise çalışanların yapılan hileli işlemi haklı gösterme davranışı içine girmeleridir. Mali durumu bozuk olan bir çalışanın parayı ödünç aldığını, durumu düzeldiğinde tekrar aldığı parayı yerine koyacağını söylemesi veya verdiği emek karşılığında aldığı ücretin çok düşük olduğunu bahane ederek yaptığı davranışı haklı gösterme davranışı içine girmesi buna örnek gösterilebilir (Aktar, 2016).

Wolfe ve Hermanson (2004) bu üçlüye bir değişken daha ekleyerek olması gereken hile unsurunu Şekil 3'teki gibi tanımlamışlardır. Yetkinlikler (Capability) adı verilen bu yeni unsur, kişinin doğuştan gelen yeteneklerinin ve sonradan kazanılan becerilerinin hile unsurları arasında yer alması gerektiğini değerlendirmişlerdir. Wolfe ve Hermanson (2004) göre yüksek tutarlı hileler yeterli yetkinliğe sahip kişilerin bir araya gelmesi ile gerçekleşmektedir. Hile yapacak kişilerde bulunması gereken yetkinlikler ise pozisyonu, zeka seviyesi, yüksek ego, kendine güven duygusu, ikna yeteneği, sürekli ve etkin yalan söyleme becerisi, stresle başa çıkabilmesi vb. olarak tanımlanmaktadır.

\subsection{Hile Türleri}

Hile türlerini işletme içi ve işletme dışı, kayıt içi ve kayıt dışı, sistematik ve sistematik olmaması gibi farklı başlıklar altında sınıflandırmak mümkündür. Literatürde genellikle hileli işlemler beş grupta toplanmaktadır.

a. Yönetim Hileleri: İşletme yöneticilerinin finansal tablo kullanıcılarını (yatırımcılar, hissedarlar, devlet, finansal kuruluşlar, vb.) yanıltmak amacıyla yaptığı işlemlerdir. Burada asıl amaç işletmenin durumunun olduğundan çok daha iyi veya çok daha kötü gösterilmesi işlemidir. Özellikle işletme yöneticilerin bu tip işlemlere başvurmalarının sebebi vergi kaçırmaktır. Halka açık işletmelerde ise durum biraz farklıdır. Halka açık işletmeler, 
durumlarını iyi göstermeye çalışarak şirketin piyasa değerini artırma ve düşük maliyetle kredi sağlamayı düşünmektedir. Hileli işlemlerle işletmenin büyüklüğü ile işletmenin kendisini daha iyi veya daha kötü göstermesi arasında bir ilişki bulunmaktadır. Küçük ve orta ölçekli işletmelerin kendilerini olduğundan daha kötü gösterme eğilimi içinde oldukları; özellikle halka açık büyük işletmelerin ise tam tersi olarak finansal durumlarını olduğundan daha iyi gösterme eğilimi içine girebilecekleri görülmüştür (Ertekin, 2017:75).

b. Çalışan Hileleri: İşletme çalışanlarının kişisel çıkarları için işletme kaynaklarını kullanması veya zimmet ve hırsılık yoluyla ele geçirmesidir (Bozkurt, 2000:3-5). Yapılan araştırmalarda işletmeye ilk gelen ve son çıkan çalışanların hileli işlem yapma eğilimlerinin daha fazla olduğu tespit edilmiştir (Ertekin, 2012:77).

ACFE raporuna göre hileli işlem yapanların \%69'unun erkek; \%31'nin ise kadın çalışandır. Erkek çalışanların hileli davranışlardan dolayı verdiği kayıpların medyanı 156.000 \$ iken kadın çalışanlarda bu tutar 89.000\$ olarak raporlanmıştır. Çalışanların görev sürelerindeki artışla daha güvenilir görünmeleri ve bu yüzden fazla denetlenmemelerinin hileli davranışa zemin hazırladığı ACFE raporunda belirtilmiştir.

Tablo 2. Görev Sürelerine Göre Hileli İşlem Yapan Çalışanların Yüzdesel Dağılımı

\begin{tabular}{|l|c|c|}
\hline Görev Süresi & Olay & Kayıp (Medyan) \\
\hline 1 y1ldan az & $\% 9$ & $40.000 \$$ \\
\hline $1-5$ Y1l & $\% 44$ & $100.000 \$$ \\
\hline $6-10$ y1l & $\% 23$ & $173.000 \$$ \\
\hline 10 y1ldan daha fazla & $\% 24$ & $241.000 \$$ \\
\hline
\end{tabular}

Kaynak: ACFE Report (2018)

Özellikle uzun yıllar aynı işletmede çalışan kişilerin sistemin bütün açıklarını bilmeleri hileli işlemlere başvurma olasılıkları arttırabilmektedir. ACFE'in 2018 raporunda 10 y1l ve üzeri çalışan personelin \%24'nün hileli işlemlere başvurduğu raporlanmıştır. Tablo 2'ye göre çalışanlar tarafından hileli işlemler en çok 1-5 yıllık hizmet sürelerinde yapılsa da en fazla kaybı veren $241.000 \$$ ile 10 yıl ve üzeri çalışan personelin olduğu gruptur.

c. Yatırım Hileleri: Değeri olmayan veya hiç yapılmayan yatırımların yatırımcılara satılması sonucu doğan hilelerdir. Ponzi hilesi, piramit hilesi, vb.

ç. Satıcı Hileleri: Satıcının işletme içinden kişilerle anlaşarak veya tek başına yaptığı hile türleridir. Örneğin satıcının düşük kaliteli mal satması, satış tutarını fazla göstermesi, eksik mal teslim etmesi, vb.

d. Müşteri Hileleri: Müşterinin aldığı mal veya hizmet karşılığında satıcıyı aldatmaya çalışarak zarar vermesine sebep olan hile türleridir. Örneğin müşterinin malın gerçek fiyatının altında ödeme yapması ve ya hiç ödeme yapılmadan mal veya hizmeti satın alması örnek gösterilebilir. 


\section{HILLE DENETIMINDE PROAKTİF YÖNTEMLER}

Hile ile ilgili bir şikayet alındıktan sonra ya da hileli bir durumun ortaya çıkmasından sonra yapılan hile incelemesi reaktif bir yaklaşımın sonucu iken daha tehditler doğmadan öngörerek önlem alan yaklaşım proaktif bir yaklaşımın sonucudur. Proaktif yaklaşımlara örnek olarak sürekli denetim yöntemleri, veri madenciliği uygulamaları (Sınıflandırma, kümeleme yöntemleri, yapay sinir ağları, genetik algoritmalar, karar ağaçları vb istatistiki yöntemler) ve Benford yasası temelli olan analitik inceleme teknikleri, analitik inceleme prosedürleri (Rasyo analizleri, trend analizi) verilebilir.

Söz konusu bu yöntemler arasından Benford yasası, insanın rastgele davranmayacağını varsaymaktadır. İnsanlar hile yapmak amacıyla sayı üretmeye çalıştıklarında birkaç numarayı tekrar edecekleri noktasından yola çıkarak hileli işlemlerin tespit edilebileceğini öngörmektedir. Benford yasasının temel mantığında her bir değişkene ilişkin beklenen ve gözlemlenen dağılımların karşılaştırılması suretiyle verilerin gerçeğe uygunluğu test edilmektedir. Gerçek ile beklenen değerler arasında fark (sapma) olması durumunda bu işlemler üzerinde daha fazla durulması gerektiği ifade edilmektedir.

Benford yasasının ilk ortaya çıkaran Amerikalı matematikçi ve astronom olan Simon Newcomb'dur. Newcomb logaritma kitaplarının ilk sayfalarının diğer sayfalara göre daha fazla kirli olduğunu ve daha fazla kullanıldığını görmüş ve buradan rakamların her basamakta çıkma olasılıklarını farklı olacağını düşünmüştür. Her ne kadar Newcomb'un bu teorisi yeterli ilgiliyi ilk başta görmese de 1938 yılında fizikçi Frank Benford'un "The Law of Anomalous Number" isimli makalesinde Newcomb'un çalışmasına benzer bir çalışmayı birçok alan için yapmış olması kısa sürede ilgi çekmiş ve Benford yasası olarak bilinen kuralların doğmasını sağlamıştır (Türkyener, 2007:111-121).

Benford yaptığı araştırmada homojen dağıldı̆̆ı düşünülen sayıların gerçekte logaritmik bir dağılım sergilediklerini ortaya koymuştur.



Şekil 4. Benford Yasasına Göre Rakamların Ortaya Çıkma Sıklı̆̆ı

Şekil 4'e göre 1-9 arasından ilk rakamın 1 olma olasılığını 1/9 (\%11,11) değil \%30,10 olduğu görülmektedir. 
Sifirdan farklı olan bir rakamın,

- Sayının ilk basamağında olma olasılığı;

$$
P\left(d_{1}\right)=\log _{10}\left(1+\frac{1}{d}\right), \quad d_{1}=1,2,3, \ldots, 9
$$

Örneğin, 8 rakamının ilk basamakta çıkma olasılığı,

$$
P(8)=\log _{10}\left(1+\frac{1}{8}\right)=0,05115
$$

- Sayının ikinci basamağında olma olasılı̆̆g;

$$
P\left(d_{2}\right)=\sum_{d=1}^{9} \log \left(1+\frac{1}{d_{1} d_{2}}\right), \quad d_{2}=0,1,2,3, \ldots, 9
$$

Örneğin, 8 rakamının ikinci basamakta çıkma olasılı̆̆ı,

$$
P(8)=\log \left(\frac{19}{18}\right)+\log \left(\frac{29}{28}\right)+\log \left(\frac{39}{38}\right)+\cdots+\log \left(\frac{99}{98}\right)=0,08757
$$

- Sayının ilk iki basamağında olma olasılı̆̆ı;

$$
P\left(d_{1}, d_{2}\right)=\log \left(1+\frac{1}{d_{1} d_{2}}\right), \quad d_{1} d_{2}=10,11,12, \ldots, 99
$$

Örneğin, birinci basamakta 1, ikinci basamakta 8 rakamının çıkma olasılığı,

$$
P(18)=\log \left(\left(1+\frac{1}{18}\right)\right)=0,02348
$$

olarak gösterilmiştir Benford yasasının geçerli olabilmesi; verilerin homojen olmasına, alt ve üst sınır aralıklarının belirlenmemiş olmasına, verilerin kodlanmamış olmasına ve artan şekilde sıralandığında geometrik bir devamlılıkla takip etmesine bağlıdır (Akkaş, 2007:191206).

\section{UYGULAMA}

\subsection{Yöntem ve Varsayımlar}

Hileli işlemlerdeki temel unsur insan olduğu için hileli davranışların önceden tahmin edilmesiyle hileli işlemlerin ortaya çıkartılması mümkün olabilecektir. İki farklı çalışmada söz konusu bu bulguyu destekler sonuçlara ulaşılmıştır. İlk araştırmada çalışanların $\% 10$ 'nunun her durumda hile yaptıkları, \%15'lik kesiminin hiçbir ortam veya durumda hile yapmadıkları ve \%75'lik bölümün ise uygun bir firsat bulduklarında hile yaptıkları ortaya konmuştur. Buna benzer olarak yapılan başka bir araştırmada ise \%20'lik kısmının her durumda hile yaptıkları, \%60'lık kısmının ise uygun firsat bulduklarında hile yaptıkları görülmüştür. Buna göre insanların yaklaşık \%70'lik kesimi için uygun ortam oluştuğunda 
hileli davranışlar sergileyebileceği sonucu çıkmaktadır (Erdem, 2014:16). Başka bir çalışmada muhasebede ve denetlemede yönetim muhasebesi ve denetim faaliyetlerinde kişisel yargıların kullanılması ile muhasebenin insan davranışlarının bir sonucunu yansıtacağı görüşü benimsenmiştir (Marşap ve Gökten, 2016:354). Bu çalışmalar hilede temel unsurun insan olduğu varsayımını doğrulamaktadır.

Literatürdeki yapılan çalışmaların çıkış yönünün tersine yapılan hileli bir davranışı bulmaya değil, hileli bir davranışı yapmaya yönelik bir araştırmanın dizayn edilmesi durumunda insan davranışlarının bilişsel düzeyinin daha iyi anlaşılabileceği varsayılmıştır. Bunun için katılımcılara farklı senaryolar sorularak hileli bir işlem yapması istenirse bunu nasıl kurguladığı tespit edilmeye çalışılmıştır. Varsayımların doğrulanması durumunda yapılan hilelerin bulunmasında farklı bir bakış açısı ile söz konusu bilgilerin finansal tablo denetimine aktarılması mümkün olabilecektir.

\subsection{Veri}

Araştırma iki kısımdan oluşmaktadır. İlk kısımda bir durum veya koşul verilmeden 177 kişiden belli aralıklara ilişkin rassal sayı üretmeleri istenmiştir. Buradaki amaç farklı türden sayı aralıklarına ilişkin rassal sayı üretiminde insanların kendi zihinlerinde oluşturdukları bir sistematiğin olup olmadığının tespit edilmesidir. Araştırmanın ikinci kısımda ise senaryolarla hileli bir davranış için katılımcılardan sayı üretmeleri istenmiştir. Aşağıda senaryolara ilişkin örnek sorular gösterilmektedir.

\section{Senaryo 1:}

Ahmet Bey, ünlü bir mağazada kasiyer olarak çalışmaktadır. Çalışma koşulları çok ağırdır. Resmi tatiller günleri dâhil olmak üzere patronu tarafindan 07.00- 21.30 saatleri arasında mesai yapmaya zorlanmaktadır. Kızının rahatsızlığında bile doktora gitmek için patronundan çok zor izin almıştır. Ahmet Bey, patronundan intikam alarak onu cezalandırmayı düşünmektedir. Satış tutarları ile oynayarak elde edeceği parayı çocuğunun sağlığına kavuşması için kullanmayı düşünmektedir. Şirketin 1 aylık günlük bazda satış tutarları aşağıda verilmiştir. Ahmet Bey, şirket hesaplarının çok sıkı olarak denetlendiğinin farkındadır. Buna göre sizce boş olan alanlara hangi tutarlar yazılırsa Ahmet Bey'in yapmış olduğu işlem anlaşılamaz?

\begin{tabular}{|l|l|l|}
\hline Günler & Satış Miktarı & Satış Tutarı \\
\hline 1.Oca.19 & 21 & 2060 \\
\hline 2.Oca.19 & 27 & 3472 \\
\hline 3.Oca.19 & 15 & 2412 \\
\hline 4.Oca.19 & 18 & 2236 \\
\hline 5.Oca.19 & 30 & 804 \\
\hline 6.Oca.19 & 27 & \\
\hline 7.Oca.19 & 21 & 578 \\
\hline 8.Oca.19 & 6 & 2784 \\
\hline 9.Oca.19 & 8 & 260 \\
\hline
\end{tabular}

\begin{tabular}{|l|l|l|}
\hline Günler & $\begin{array}{l}\text { Satı̧s } \\
\text { Miktarı }\end{array}$ & Satış Tutarı \\
\hline 16.Oca.19 & 6 & 208 \\
\hline 17.Oca.19 & 15 & 412 \\
\hline 18.Oca.19 & 9 & 2884 \\
\hline 19.Oca.19 & 6 & \\
\hline 20.Oca.19 & 12 & 3296 \\
\hline 21.Oca.19 & 18 & \\
\hline 22.Oca.19 & 5 & 3708 \\
\hline 23.Oca.19 & 3 & 412 \\
\hline 24.Oca.19 & 12 & \\
\hline
\end{tabular}




\begin{tabular}{|l|l|l|} 
10.Oca.19 & 18 & \\
\hline 11.Oca.19 & 10 & 648 \\
\hline 12.Oca.19 & 6 & \\
\hline 13.Oca.19 & 24 & 2884 \\
\hline 14.Oca.19 & 12 & \\
\hline 15.Oca.19 & 24 & 2920 \\
\hline
\end{tabular}

\begin{tabular}{|l|l|l|} 
25.Oca.19 & 18 & 648 \\
\hline 26.Oca.19 & 9 & 824 \\
\hline 27.Oca.19 & 27 & 708 \\
\hline 28.Oca.19 & 14 & 402 \\
\hline 29.Oca.19 & 6 & 2472 \\
\hline 30.Oca.19 & 27 & \\
\hline 31. Oca.19 & 9 & 2536 \\
\hline
\end{tabular}

\section{Senaryo 2:}

Müfettiş olarak bir şirketin hesaplarını denetlemek için görevlendirildiniz. Şirket çalışanı size günlük satış tutarlarını gösteren çizelgeyi uzattı. Listedeki bazı tutarlar aşağıda verilmiştir. Sizce aşağıdaki verilen her grup arasındaki hangi sayıda bir oynanma (hile) ihtimali olabilir? Lütfen her gruptan sadece birini işaretleyiniz.

\begin{tabular}{|c|c|c|}
\hline I.GRUP & II.GRUP & III.GRUP \\
\hline $\begin{array}{c}120 \mathrm{TL} \\
10.000 \mathrm{TL} \\
140 \mathrm{TL} \\
100 \mathrm{TL} \\
14.000 \mathrm{TL} \\
12.000 \mathrm{TL}\end{array}$ & $\begin{array}{l}.000 \mathrm{TL} \\
6.532 \mathrm{TL} \\
6.000 \mathrm{TL} \\
5.842 \mathrm{TL} \\
4.000 \mathrm{TL} \\
4.732 \mathrm{TL}\end{array}$ & $\begin{array}{l}\square \% 20,00 \\
\% 24,34 \\
\% 21,47 \\
\% 22,56 \\
\% 28,00 \\
\% 26,42\end{array}$ \\
\hline $\begin{array}{l}\text { IV.GRUP } \\
\square 1.532,32 T L \\
1.560,00 T L \\
1.518,48 T L \\
1.480,00 T L \\
1.430,73 T L \\
1.516,00 T L\end{array}$ & 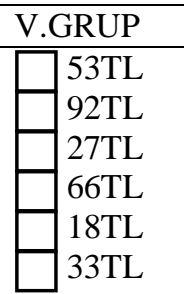 & $\begin{array}{l}\text { VI.GRUP } \\
\square 432,64 T \mathrm{TL} \\
400,00 \mathrm{TL} \\
419,42 \mathrm{TL} \\
480,00 \mathrm{TL} \\
530,23 \mathrm{TL} \\
516,00 \mathrm{TL}\end{array}$ \\
\hline
\end{tabular}

Ana örneklem grubuna uygulamadan önce 46 kişilik küçük bir gruba hazırlanan senaryolar uygulanmıştır. 46 kişilik küçük gruptan alınan bilgiler 1şığında araştırma dizayn edilerek 192 kişiye tekrar uygulanmıştır. Veriler üzerinde yapılan incelemede bazı katılımcıların soruların büyük bir kısmını yanıtlamadıkları görülmüştür. Bu katılımcıların cevapları araştırma verisinden çıkartılarak toplamda 177 kişinin cevapları değerlendirmeye alınmıştır.

\subsection{Analiz}

Çalışmanın birinci kısmı insanların rassal sayı üretiminde kullandıkları örüntüleri tespit etmektir. Bunu tespit etmek için kurulan hipotezler istatistiksel olarak test edilerek rassal sayı üretimine ilişkin örüntülerin ortaya çıkartılması amaçlanmaktadır. Aşağıda her bir hipoteze ilişkin analiz sonuçları gösterilmektedir. 
- İnsanlar tarafından üretilen rassal sayıların belli bir dağılıma uygun (normal dağılım, uniform dağılım, poisson, exponential) olup olmadığının tespiti için,

Ho: Insanlar rassal (tesadüfi) sayı üretimini belli bir sistematik içinde yapmaz.

$H_{1}$ : Insanlar rassal (tesadüfi) sayı üretimini belli bir sistematik içinde yapar.

İnsanlar rassal sayı üretimini belli bir sistematik içinde yapmıyorlarsa, ürettikleri rassal sayıların belli bir dağılıma uyacağı varsayılmaktadır. Bunu test etmek için en çok bilenen dağılım türleri kullanılarak bir değerlendirme yapılmıștır. Öncelikle bilgisayara normal dağılıma uygun olarak her seferinde 15 adet olacak şekilde 177 kez sayı ürettirilmiş ve dağılım sonuçları Tablo 3’te gösterilmiştir.

Rassal sayılar normal dağılıma uygun olarak üretildikleri için normal dağılıma uygun olduğu ve aynı zamanda rassal üretilmesi sebebiyle Uniform dağılıma da uydukları Tablo 3'te görülmektedir.

Tablo 3. Bilgisayar Tarafından Üretilen Rassal Sayıların Dağılım Sonuçları

\begin{tabular}{|c|c|c|c|}
\hline Dağlım & $\mathrm{n}$ & $\begin{array}{c}\text { K-S Test } \\
\text { Değeri }\end{array}$ & $\begin{array}{c}\text { Asymp. Sig. } \\
\text { (p) }\end{array}$ \\
\hline Normal & 177 & 0,759 & $\mathbf{, 6 1 2}$ \\
\hline Uniform & 177 & 1,091 & $\mathbf{, 1 8 5}$ \\
\hline Poisson & 177 & - & - \\
\hline Exponential & 177 & 2,838 &, 000 \\
\hline
\end{tabular}

Katılımcılar tarafindan üretilen rassal sayıların sonuçları ise Tablo 4'te gösterilmektedir. Katılımcılar tarafından üretilen rassal sayılar test edilen hiçbir dağılıma uymamakta veya söz konusu dağılımlardan gelmemektedir. Bu sonuç insanların rassal sayı üretimlerini belli bir sistematik içinde yapmış oldukları varsayımını doğrulamaktadır. Rassal olarak üretildiği düşünülen sayıların aslında rassal olmayıp insanların kendi mental hesaplamaları sonucunda belli bir sistematik içinde yapıldığını kanıtlamaktadır.

Tablo 4. Katılımcılar Tarafından Üretilen Rassal Sayıların Dağılım Sonuçları

\begin{tabular}{|l|c|c|c|}
\hline Dağılım & $\mathrm{n}$ & $\begin{array}{c}\text { K-S Test } \\
\text { Değeri }\end{array}$ & $\begin{array}{c}\text { Asymp. Sig. } \\
(\mathrm{p})\end{array}$ \\
\hline Normal & 177 & 6,890 &, 000 \\
\hline Uniform & 177 & 13,212 &, 000 \\
\hline Poisson & 177 & 13,228 &, 000 \\
\hline Exponential & 177 & 12,757 &, 000 \\
\hline
\end{tabular}


Bu yorum yapılırken 57 farklı dağılım türünün hepsi denenmemiştir. Bundan sonraki yapılacak çalışmalarda konu daha derinlemesine inilerek her bir dağılım türü ayrı ayrı incelenip, sapmanın olması durumunda hileli işlemlerin tespitinde yol gösterici bir unsur olarak kullanılabilecektir.

- Rassal üretilen çift ve tek sayılar arasında fark olup olmadığının tespiti için,

$H_{o}$ : Insanlar tarafindan üretilen rassal sayıların tek veya çift olması arasında anlamlı bir farklılık yoktur.

$H_{1}$ : Insanlar tarafindan üretilen rassal sayıların tek veya çift olması arasında anlamlı bir farklılık vardır.

İnsanlar rassal sayı üretimini belli bir sistematik içinde yapmıyor ise ürettikleri rassal sayıların tek veya çift olması arasında anlamlı bir farklılığın olmaması beklenmektedir. $\mathrm{Bu}$ varsayımı test etmek için bilgisayara her seferinde 15 adet olacak şekilde $177 \mathrm{kez}$ sayı ürettirilmiş ve bu sayıların tek mi, çift mi oldukları belirlenmiştir. Üretilen sayıların tek veya çift sayı olması arasında anlamlı bir farklılığın olup olmadığını belirlemek için Paired Samples T-Test kullanılmış ve sonuçları Tablo 3 'te gösterilmiştir.

Tablo 5. Bilgisayar Tarafından Üretilen Rassal Sayıların Tek veya Çift Sayı Olmasına İlişkin Analiz Sonuçları

\begin{tabular}{|c|c|c|c|c|c|}
\hline \multicolumn{1}{|c|}{ Say1 } & $\mathrm{n}$ & Ortalama & Std. Sapma & $\mathrm{Z}$ & $\begin{array}{c}\text { Asymp. Sig. } \\
\text { (p) }\end{array}$ \\
\cline { 1 - 4 } Tek & 177 & 7,37 & 2,096 & \multirow{2}{*}{,- 807} & \multirow{2}{*}{, 421} \\
\cline { 1 - 4 } Çift & 177 & 7,63 & 2,096 & & \\
\hline
\end{tabular}

Tablo 5'e göre bilgisayar tarafından üretilen rassal sayıların tek veya çift olması arasında anlamlı bir farklılık bulunmamaktadır. Aynı durum katılımcıların ürettikleri rassal sayılar için test edildiğinde sonuçları Tablo 6' dadır. 
Tablo 6. Aralık Verilmeden Katılımcılar Tarafından Üretilen Rassal Sayıların Tek veya Çift Sayı Olmasına İlişkin Analiz Sonuçları

\begin{tabular}{|c|c|c|c|c|c|}
\hline \multicolumn{1}{|c|}{ Say1 } & $\mathrm{n}$ & Ortalama & Std. Sapma & $\mathrm{Z}$ & $\begin{array}{c}\text { Asymp. Sig. } \\
\text { (p) }\end{array}$ \\
\cline { 1 - 4 } Tek & 177 & 2,59 & 1,346 & \multirow{2}{*}{,- 977} & \multirow{2}{*}{, 329} \\
\cline { 1 - 4 } Çift & 177 & 2,41 & 1,346 & & \\
\hline
\end{tabular}

\begin{tabular}{|c|c|c|c|c|c|c|c|}
\hline \multirow{2}{*}{\multicolumn{2}{|c|}{ Cinsiyet }} & \multicolumn{2}{|c|}{ Sayı } & \multirow{3}{*}{$\begin{array}{r}\text { Toplam } \\
110\end{array}$} & \multirow{3}{*}{$x^{2}$} & \multirow{2}{*}{$\mathrm{df}$} & \multirow{2}{*}{ Asymp. Sig } \\
\hline & & \multirow{2}{*}{$\begin{array}{c}\text { Tek } \\
57\end{array}$} & \multirow{2}{*}{$\frac{\text { Çift }}{53}$} & & & & \\
\hline \multirow{2}{*}{ Kadın } & Gözlenen Sıklık & & & & & \multirow{6}{*}{1} & \multirow{6}{*}{,526 } \\
\hline & Beklenen Siklık & 59,0 & 51,0 & 110,0 & \multirow{5}{*}{,402 } & & \\
\hline \multirow{2}{*}{ Erkek } & Gözlenen Sıklık & 38 & 29 & 67 & & & \\
\hline & Beklenen Sıklık & 36,0 & 31,0 & 67,0 & & & \\
\hline \multirow{2}{*}{ Toplam } & Gözlenen Sıklık & 95 & 82 & 177 & & & \\
\hline & Beklenen Sıklık & 95,0 & 82,0 & 177,0 & & & \\
\hline
\end{tabular}

Aralık verilmeden katılımcılar tarafından üretilen rassal sayıların Tek veya Çift olması arasında anlamlı bir farklılığın olmadığı görülmektedir. Cinsiyete göre bakıldığında da aralarında bir farklılık görülmemiştir. Aralık verilmeden üretilen rassal sayılara ilişkin analiz yapıldığında bir farklılık yok ise aralık verilerek aynı olay tekrarlandığında yani katılımcılara sayıları belli aralıklar için üretmeleri istendiğinde söz konusu durumun değişip değişmediği kontrol edilmiştir.

Tablo 7. 0-10 Aralığında Katılımcılar Tarafından Üretilen Rassal Sayıların Tek veya Çift Olmasına İlişsin Analiz Sonuçları

\begin{tabular}{|c|c|c|c|c|c|}
\hline \multicolumn{1}{|c|}{ Say1 } & $\mathrm{n}$ & Ortalama & Std. Sapma & $\mathrm{Z}$ & $\begin{array}{c}\text { Asymp. Sig. } \\
\text { (p) }\end{array}$ \\
\cline { 1 - 3 } Tek & 177 & 3,05 & 1,078 & \multirow{2}{*}{$-6,191$} & $\mathbf{0 0 0}$ \\
\cline { 1 - 4 } Çift & 177 & 1,95 & 1,078 & & \\
\hline
\end{tabular}

\begin{tabular}{|c|c|c|c|c|c|c|c|}
\hline \multirow{2}{*}{\multicolumn{2}{|c|}{ Cinsiyet }} & \multicolumn{2}{|c|}{ Say1 } & \multirow{3}{*}{\begin{tabular}{|r|} 
Toplam \\
110
\end{tabular}} & \multirow{3}{*}{$x^{2}$} & \multirow{2}{*}{$\mathrm{df}$} & \multirow{2}{*}{$\begin{array}{l}\text { Asymp. Sig } \\
\text { (p) }\end{array}$} \\
\hline & & Tol & Cif & & & & \\
\hline \multirow{2}{*}{ Kadın } & Gözlenen Sıklık & 81 & 29 & & & \multirow{6}{*}{1} & \multirow{6}{*}{ 475 } \\
\hline & Beklenen Siklık & 78,9 & 31,1 & 110,0 & \multirow{5}{*}{,509 } & & \\
\hline \multirow{2}{*}{ Erkek } & Gözlenen Sıklık & 46 & 21 & 67 & & & \\
\hline & Beklenen Siklık & 48,1 & 18,9 & 67,0 & & & \\
\hline \multirow{2}{*}{ Toplam } & Gözlenen Sıklık & 127 & 50 & 177 & & & \\
\hline & Beklenen Siklık & 127,0 & 50,0 & 177,0 & & & \\
\hline
\end{tabular}


Tablo 7’ye göre katılımcılardan 0-10 aralığında sayı üretmeleri istendiğinde ürettikleri tek sayılarla çift sayılar arasında anlamlı bir farklılığın olduğu görülmektedir. Bu aralık için rassal sayı oluştururken daha çok tek sayı üretme eğilimi içinde oldukları tespit edilmiştir. $\mathrm{Bu}$ durum insanların belli bir sistematik içinde mental hesaplamaları yaptığını doğrular nitelikteki başka bir kanıttır.

Tablo 8. 0-1.000 Aralığında Katılımcılar Tarafından Üretilen Rassal Sayıların Tek veya Çift Olmasına İlişkin Analiz Sonuçları

\begin{tabular}{|l|c|c|c|c|c|}
\hline \multicolumn{1}{|c|}{ Say1 } & $\mathrm{n}$ & Ortalama & Std. Sapma & $\mathrm{Z}$ & $\begin{array}{c}\text { Asymp. Sig. } \\
\text { (p) }\end{array}$ \\
\cline { 1 - 3 } Tek & 177 & 2,22 & 1,512 & \multirow{2}{*}{$-2,215$} & \multirow{2}{*}{027} \\
\cline { 1 - 4 } Çift & 177 & 2,78 & 1,512 & & \\
\hline
\end{tabular}

\begin{tabular}{|c|c|c|c|c|c|c|c|}
\hline \multirow{2}{*}{\multicolumn{2}{|c|}{ Cinsiyet }} & \multicolumn{2}{|c|}{ Sayı } & \multirow{3}{*}{$\begin{array}{c}\text { Toplam } \\
110\end{array}$} & \multirow{2}{*}{$x^{2}$} & \multirow{2}{*}{$\mathrm{df}$} & \multirow{2}{*}{$\begin{array}{l}\text { Asymp. Sig. } \\
\text { (p) }\end{array}$} \\
\hline & & Tek & Cift & & & & \\
\hline \multirow{2}{*}{ Kadın } & Gözlenen Sıklık & 49 & 61 & & \multirow{6}{*}{ 988 } & \multirow{6}{*}{1} & \multirow{6}{*}{,320 } \\
\hline & Beklenen S1klık & 52,2 & 57,8 & 110,0 & & & \\
\hline \multirow{2}{*}{ Erkek } & Gözlenen Sıklık & 35 & 32 & 67 & & & \\
\hline & Beklenen Siklık & 31,8 & 35,2 & 67,0 & & & \\
\hline \multirow{2}{*}{ Toplam } & Gözlenen Sıklık & 84 & 93 & 177 & & & \\
\hline & Beklenen Sıklık & 84,0 & 93,0 & 177,0 & & & \\
\hline
\end{tabular}

Sayı aralığı değiștirilerek katılımcılardan bu sefer 0-1.000 aralığında rassal sayı üretmeleri istendiğinde Tablo 8'deki sonuçlara göre ürettikleri tek ve çift sayılar arasında anlamlı bir farklılığın olduğu ve bu aralıkta çift sayı üretme eğilimi içinde oldukları tespit edilmiştir. $\mathrm{Bu}$ durum insanların farklı sayı aralıklarında olayı kendi zihinlerinde farklılaştırarak sayı ürettiklerini göstermektedir.

Tablo 9. 0-1.000.000 Aralığında Üretilen Rassal Sayıların Tek veya Çift olmasına İlişkin Analiz Sonuçları

\begin{tabular}{|c|c|c|c|c|c|}
\hline \multicolumn{1}{|c|}{ Say1 } & $\mathrm{n}$ & Ortalama & Std. Sapma & $\mathrm{Z}$ & $\begin{array}{c}\text { Asymp. Sig. } \\
(\mathrm{p})\end{array}$ \\
\cline { 1 - 3 } Tek & 177 & 1,53 & 1,302 & \multirow{2}{*}{$-7,994$} & \multirow{2}{*}{, 000} \\
\cline { 1 - 4 } Çift & 177 & 3,47 & 1,302 & \\
\hline
\end{tabular}

\begin{tabular}{|l|l|c|c|c|c|c|c|}
\hline \multirow{2}{*}{ Cinsiyet } & \multicolumn{2}{|c|}{ Sayı } & \multirow{2}{*}{ Toplam } & $\mathrm{x}^{2}$ & $\mathrm{df}$ & $\begin{array}{c}\text { Asymp. Sig. } \\
\text { (p) }\end{array}$ \\
\cline { 3 - 7 } & Tek & Çift & & \multirow{2}{*}{, 232} & 1 &, 630 \\
\hline \multirow{2}{*}{ Kadın } & Gözlenen S1klık & 26 & 84 & 110 & 110,0 & \\
\cline { 2 - 5 } & Beklenen S1kl1k & 27,3 & 82,7 & 10 & \\
\hline
\end{tabular}






Aralık daha da büyütülerek 0-1.000.000 aralığında rassal sayı üretmeleri istendiğinde ise Tablo 9'daki sonuçlara göre aralarında anlamlı bir farklılığın olduğu ve yine daha çok çift sayılara ilişkin sayı üretme eğilimi içinde oldukları gözlemlenmiştir. Cinsiyete göre anlamlı bir fark tespit edilmemiş olması hem kadın hem de erkeklerin bu sayı aralığı için çift sayı oluşturma eğiliminde olduklarını göstermektedir.

Tablo 10. 0 - 1 Aralığında Üretilen Rassal Sayıların Tek veya Çift olmasına İlişkin Analiz Sonuçları

\begin{tabular}{|l|c|c|c|c|c|}
\hline \multicolumn{1}{|c|}{ Say1 } & $\mathrm{n}$ & Ortalama & Std. Sapma & $\mathrm{Z}$ & $\begin{array}{c}\text { Asymp. Sig. } \\
\text { (p) }\end{array}$ \\
\cline { 1 - 4 } Tek & 177 & 2,83 & 1,218 & \multirow{2}{*}{$-3,983$} &, 000 \\
\cline { 1 - 4 } Çift & 177 & 2,17 & 1,218 & \\
\hline
\end{tabular}

\begin{tabular}{|c|c|c|c|c|c|c|c|}
\hline \multirow{2}{*}{\multicolumn{2}{|c|}{ Cinsiyet }} & \multicolumn{2}{|c|}{ Say1 } & \multirow{3}{*}{\begin{tabular}{|l|} 
Toplam \\
110
\end{tabular}} & \multirow{2}{*}{$x^{2}$} & \multirow{2}{*}{$\mathrm{df}$} & \multirow{2}{*}{ Asymp. Sig } \\
\hline & & Tek & Çift & & & & \\
\hline \multirow{2}{*}{ Kadın } & Gözlenen S1klık & 82 & 28 & & \multirow{6}{*}{4,284} & \multirow{6}{*}{1} & \multirow{6}{*}{ 038 } \\
\hline & Beklenen Sıklık & 75,8 & 34,2 & 110,0 & & & \\
\hline \multirow{2}{*}{ Erkek } & Gözlenen Sıklık & 40 & 27 & 67 & & & \\
\hline & Beklenen Sıklık & 46,2 & 20,8 & 67,0 & & & \\
\hline \multirow{2}{*}{ Toplam } & Gözlenen Sıklık & 122 & 55 & 177 & & & \\
\hline & Beklenen Siklık & 122,0 & 55,0 & 177,0 & & & \\
\hline
\end{tabular}

Sayı aralığı 0-1 olduğunda ise üretilen rassal sayılar Tablo 10'daki sonuçlara tek ve çift sayı üretimi arasında anlamlı bir farklılığın bulunduğu ve bu aralık için tek sayılara ilişkin sayı üretme eğilimi içinde oldukları görülmektedir. Cinsiyete göre bir farklılığın olup olmadığı da test edildiğinde özellikle kadın katılımcıların daha fazla tek sayı üretmiş oldukları gözlemlenmiştir. 
Tablo 11. \%1 - \%100 Aralığında Üretilen Rassal Sayıların Tek veya Çift olmasına İlişkin Analiz Sonuçları arasında

\begin{tabular}{|l|c|c|c|c|c|}
\hline \multicolumn{1}{|c|}{ Açıklama } & $\mathrm{n}$ & Ortalama & Std. Sapma & $\mathrm{Z}$ & $\begin{array}{c}\text { Asymp. Sig. } \\
\text { (p) }\end{array}$ \\
\cline { 1 - 3 } Tek & 177 & 2,15 & 1,336 & \multirow{2}{*}{$-3,103$} & \multirow{2}{*}{, 002} \\
\hline Çift & 177 & 2,85 & 1,336 & \\
\hline
\end{tabular}

\begin{tabular}{|c|c|c|c|c|c|c|c|}
\hline \multirow{2}{*}{\multicolumn{2}{|c|}{ Cinsiyet }} & \multicolumn{2}{|c|}{ Say 1} & \multirow{3}{*}{\begin{tabular}{|r} 
Toplam \\
110 \\
\end{tabular}} & \multirow{3}{*}{$x^{2}$} & \multirow{2}{*}{$\mathrm{df}$} & \multirow{2}{*}{$\begin{array}{l}\text { Asymp. Sig } \\
\text { (p) }\end{array}$} \\
\hline & & Tek & Cift & & & & \\
\hline \multirow{2}{*}{ Kadın } & Gözlenen Sıklık & 51 & 59 & & & \multirow{6}{*}{1} & \multirow{6}{*}{ 431 } \\
\hline & Beklenen Sıklık & 48,5 & 61,5 & 110,0 & \multirow{5}{*}{,621 } & & \\
\hline \multirow{2}{*}{ Erkek } & Gözlenen Sıklık & 27 & 40 & 67 & & & \\
\hline & Beklenen S1klık & 29,5 & 37,5 & 67,0 & & & \\
\hline \multirow{2}{*}{ Toplam } & Gözlenen Sıklık & 78 & 99 & 177 & & & \\
\hline & Beklenen Sıklık & 78,0 & 99,0 & 177,0 & & & \\
\hline
\end{tabular}

Sayı aralığı yüzde cinsinden üretmeleri istendiğinde (\%1 - \%100) Tablo 11'deki sonuçlara göre tek ve çift sayı arasında anlamlı bir farklılı̆̆ın olduğu ve yüzdelik ifadelerde insanların daha çok çift sayı üretme eğilimi içinde oldukları görülmektedir.

- Alt ve üst sayı limitleri verilmeden insanlardan sayı üretmeleri istendiğinde bir referans noktasının üstünde mi; yoksa altında mı sayı üretme eğilimi içinde olduklarının tespiti için aşağıdaki hipotezler kurulmuştur.

Ho: Insanlara limit vermeden rassal bir sayı üretmeleri istendiğinde küçük sayı üretme eğiliminde değillerdir.

$H_{1}$ : Insanlara limit vermeden rassal bir sayı üretmeleri istendiğinde küçük sayı üretme eğilimi içindedirler.

Tablo 12. Aralık Verilmeden Üretilen Rassal Sayıların Gruplandırılmasına İlişkin Analiz Sonuçları

\begin{tabular}{|c|c|c|c|c|c|}
\hline Aralık & Gözlemlenen N & Beklenen N & $x^{2}$ & df & $\begin{array}{l}\text { Asymp. Sig. } \\
\text { (p) }\end{array}$ \\
\hline $0-50$ & 587 & 147,5 & \multirow{7}{*}{1624,024} & \multirow{7}{*}{5} & \multirow{7}{*}{,000 } \\
\hline $51-100$ & 137 & 147,5 & & & \\
\hline $101-500$ & 51 & 147,5 & & & \\
\hline 501-1.000 & 31 & 147,5 & & & \\
\hline $1.001-1.0000$ & 45 & 147,5 & & & \\
\hline 10.001-üstü & 34 & 147,5 & & & \\
\hline Total & \multicolumn{2}{|c|}{885} & & & \\
\hline
\end{tabular}


Hiçbir aralık verilmeden üretilen rassal sayılar aralıklara göre gruplandırıldığında Tablo 12'deki sonuçlar elde edilmiştir. Buna göre aralık verilmeden rassal sayı üretimi 0-50 aralığında ve küçük sayı üretme eğilimi içine girmektedir.

- Alt ve üst yüzde limitleri verilmeden rassal sayı üretimde üretilen yüzdeler bir referans noktasının üstünde mi; yoksa altında mı olduğunun tespiti için aşağıdaki hipotezler kurulmuştur.

Ho: Insanlardan \%’ye (\%1-\%100) göre sayı üretmeleri istendiğinde üretilen sayı $\%$ 0’nin altında değildir.

$H_{1}$ : Insanlardan \%’ye (\%1-\%100) göre sayı üretmeleri istendiğinde üretilen sayı $\% 50$ 'nin altındadır.

Tablo 13. Yüzdeye Göre Aralık Verilmeden Üretilen Rassal Sayıların Gruplandırılmasına İlişkin Analiz Sonuçları

\begin{tabular}{|c|c|c|c|c|c|}
\hline Aralık & Gözlemlenen N & Beklenen N & $x^{2}$ & $\mathrm{df}$ & Asymp. Sig. (p) \\
\hline$\% 1-\% 20$ & 228 & 174,2 & \multirow{6}{*}{27,008} & \multirow{6}{*}{4} & \multirow{6}{*}{,000 } \\
\hline$\% 21-\% 40$ & 134 & 174,2 & & & \\
\hline$\% 41-\% 60$ & 164 & 174,2 & & & \\
\hline \%61-\%80 & 166 & 174,2 & & & \\
\hline$\% 81-\% 100$ & 179 & 174,2 & & & \\
\hline Total & \multicolumn{2}{|c|}{871} & & & \\
\hline
\end{tabular}

\%1- \%100 aralığında rassal sayı üretildiğinde ve üretilen sayılar \%20'lik farklarla 5 aralığa bölündüğünde aralıklar arasında anlamlı bir farklılığın olduğu Tablo 13'teki sonuçlarda görülmektedir. Katılımcılar genellikle \%1-\%20 aralığında sayı üretme eğilimi içine girmişlerdir. $\mathrm{Bu}$ durum hile denetiminde, insanların hile amaçlı tutarlarda değişiklik yapmaya çalıştıklarında yapılanan hilenin bu tutarlar içinde olma olasılığının yüksek olabileceğini göstermektedir.

- İnsanlarda hileli bir davranışın küçük tutarda mı yoksa büyük tutarda mı gözüktüğüne ilişkin algıyı ölçmek için aşağıdaki hipotezler kurulmuştur.

Ho: Insanın zihinsel algısında hileli bir işlemin büyük veya küçük tutarlarda olması arasinda anlamlı bir farklılık yoktur.

$H_{1}$ : Insanın zihinsel algısında hileli bir işlemin büyük veya küçük tutarlarda olması arasinda anlamlı bir farklılık vardır. 
Tablo 14. Hileli İşlemlerin Küçük veya Büyük Tutarlarda Olacağı Algısına İlişkin Analiz Sonuçları

\begin{tabular}{|c|c|c|c|c|c|}
\hline Aralık & Gözlemlenen N & Beklenen N & $\mathrm{x}^{2}$ & $\mathrm{df}$ & $\begin{array}{l}\text { Asymp. Sig } \\
\text { (p) }\end{array}$ \\
\hline Küçük Sayılarda & 98 & 88,5 & \multirow{3}{*}{2,040} & \multirow{3}{*}{1} & \multirow{3}{*}{,153 } \\
\hline Büyük Sayılarda & 79 & 88,5 & & & \\
\hline Toplam & \multicolumn{2}{|c|}{177} & & & \\
\hline
\end{tabular}

\begin{tabular}{|c|c|c|c|c|c|c|c|}
\hline \multirow{2}{*}{\multicolumn{2}{|c|}{ Cinsiyet }} & \multicolumn{2}{|c|}{ Sayı Tutarı } & \multirow[b]{2}{*}{ Toplam } & \multirow[b]{2}{*}{$\mathrm{x} 2$} & \multirow[b]{2}{*}{$\mathrm{df}$} & \multirow[b]{2}{*}{ Asymp. Sig } \\
\hline & & Küçük & $\begin{array}{c}\text { Büyük } \\
\text { Savilarda }\end{array}$ & & & & \\
\hline \multirow{2}{*}{ Kadın } & Say1 & 63 & 47 & 110 & \multirow{6}{*}{ 427 } & \multirow{6}{*}{1} & \multirow{6}{*}{ 513, } \\
\hline & Beklenen Say 1 & 60,9 & 49,1 & 110,0 & & & \\
\hline \multirow{2}{*}{ Erkek } & Say1 & 35 & 32 & 67 & & & \\
\hline & Beklenen Say1 & 37,1 & 29,9 & 67,0 & & & \\
\hline \multirow{2}{*}{ Toplam } & Say1 & 98 & 79 & 177 & & & \\
\hline & Beklenen Say 1 & 98,0 & 79,0 & 177,0 & & & \\
\hline
\end{tabular}

Tablo 14’teki sonuçlara göre hileli işlemlerin katılımcılar gözünde küçük veya büyük tutarlarda olması arasında anlamlı bir farklılık tespit edilememiştir. Söz konusu bu durum cinsiyete göre de bakıldığında anlamlı bir farklılık yoktur. Bu durum zihinsel algıda hileli işlemlerin küçük tutarlarda da, büyük tutarlarda da görülebileceğini ifade etmektedirler.

- İnsanların hileli işlemlerin tam veya küsuratlı sayılarda görüleceğine ilişkin algılarını ölçmek için aşağıdaki hipotezler kurulmuştur.

Ho: Insanın algısında bir işlemin tam veya küsuratlı çıkması ile hileli gözükmesi arasinda anlamlı bir farklllık yoktur.

$H_{1}$ : Insanın algısında bir işlemin tam veya küsuratlı çıkması ile hileli gözükmesi arasında anlamlı bir farklılık vardır.

Tablo 15. Hileli İşlemlerin Tam veya Küsuratlı Olacağına İlişkin Analiz Sonuçları

\begin{tabular}{|l|c|c|c|c|c|}
\hline Say1 & Gözlemlenen N & Beklenen N & $\mathrm{x}^{2}$ & $\mathrm{df}$ & $\begin{array}{c}\text { Asymp. } \\
\text { Sig. (p) }\end{array}$ \\
\cline { 1 - 3 } Tam & 126 & 88,5 & \multirow{3}{*}{31,780} & \multirow{2}{*}{1} & \multirow{2}{*}{, 000} \\
\cline { 1 - 2 } Küsuratl1 & 51 & 88,5 & & & \\
\hline Total & \multicolumn{2}{|c|}{177} \\
\hline
\end{tabular}

Tablo 15'teki analiz sonuçlarına göre tam çıkan sayılarda hileli işlemlerin daha fazla olabileceği sonucu görülmektedir. Bir tutar tam çıkmış ise insan algısında hileli olma olasılığının yüksek olabileceğini göstermektedir. 
- Yüzdeli bir işlemin tam veya küsuratlı çıkması ile hileli olarak algılanması arasında bir fark olup olmadığını tespit etmek için aşağıdaki hipotezler kurulmuştur.

Ho: Insanın zihinsel algısında yüzdenin tam veya küsuratlı çıkması ile hileli gözükmesi arasında anlamlı bir farklılık yoktur.

$\mathrm{H}_{1}$ : Insanın zihinsel algısında yüzdenin tam veya küsuratlı çıkması ile hileli gözükmesi arasında anlamlı bir farklılık yoktur.

Tablo 16. Yüzdeli işlemlerin Tam veya Küsuratlı Çıkması ile Hileli Olarak Algılanmasına İlişkin Analiz Sonuçları

\begin{tabular}{|l|c|c|c|c|c|}
\hline Say1 & Gözlemlenen N & Beklenen N & $x^{2}$ & df & $\begin{array}{c}\text { Asymp. Sig. } \\
(\mathrm{p})\end{array}$ \\
\hline Tam & 96 & 88,5 & & & \multirow{2}{*}{1,271} \\
\cline { 1 - 3 } Küsuratl1 & 81 & 88,5 & \multirow{2}{*}{260} \\
\cline { 1 - 3 } Total & \multicolumn{2}{|c|}{177} & & \\
\hline
\end{tabular}

Hileli bir işlemin yüzde cinsinden yapılması durumunda yüzdenin tam veya küsüratlı çıkacağına ilişkin Tablo 16'da fark bulunmamıştır. İnsanın zihinsel algısında yüzde üzerinden yapılacak hileli bir işlem tam veya küsüratlı olarak çıkabilecektir.

- Katılımcılara tarihsel bir veri kümesi içinde hileli bir işlem yapmaları istendiğinde hile yapacağı tarihteki bir alt ve bir üst satıra bakarak mı yoksa başka tarihlerin aynı miktardaki tutarlarını baz alarak mı sayı üretip üretmediklerini tespit etmek için aşağıdaki hipotezler kurulmuştur.

Ho: Insanın zihinsel algisında belli bir periyota ilişkin hileli bir sayı üretiminde alt, üst sayıya bakılması ile aynı düzeyde veya aynı miktardaki sayılara bakılarak üretilmesi arasinda anlamlı bir farklllık yoktur.

$\mathrm{H}_{1}$ : Insanın zihinsel algisında belli bir periyota ilişkin hileli bir sayı üretiminde alt, üst sayıya bakılması ile aynı düzeyde veya aynı miktardaki sayılara bakılarak üretilmesi arasında anlamlı bir farklılık vardır.

Tablo 17. Tarihsel Veri Serisinde Hileli Bir Sayı Üretilmesine İlişskin Analiz Sonuçları

\begin{tabular}{|l|c|c|c|c|c|}
\hline \multicolumn{1}{|c|}{ Açıklama } & $\mathrm{n}$ & Ortalama & Std. Sapma & $\mathrm{Z}$ & $\begin{array}{c}\text { Asymp. Sig. } \\
\text { (p) }\end{array}$ \\
\hline Aynı Miktara Bakması & 169 & 3,69 & 1,456 & & \multirow{2}{*}{$-2,829$} \\
\cline { 1 - 4 } Bir alt veya bir üst Satıra Bakması & 169 & 4,31 & 1,456 & & \\
\hline
\end{tabular}

Tablo 17’ye göre trend içinde hileli bir işlem, aynı miktara göre değil bir önceki ve bir sonraki tarihteki tutarlara göre yapılmaktadır.

Yapılan analiz sonuçlarına göre; 
- İnsanların rassal sayı üretimlerini kendi bilişsel düzeylerinde belli bir sistematik kurala göre oluşturdukları,

- Aralık verilmeden üretilen rassal sayıların tek veya çift sayı olması arasında istatistiksel olarak anlamlı bir farklılı̆̆ın bulunmadığı,

- Aralıklara göre üretilen rassal sayıların tek veya çift sayı olması değerlendirildiğinde ise; $0-1$ ve $0-10$ aralığında tek sayıların, $0-1.000$ ve $0-1.000 .000$ aralığında çift sayıların daha

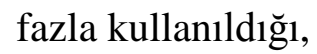

- Yüzde (\%) cinsinden daha çok çift sayıların üretildiği,

- Alt ve üst sınır verilmeden üretilen rassal sayıların 0-50 aralığında toplandı $\breve{g}$, yüzdeye (\%) göre üretilen rassal sayılarda ise \%1-\%20 aralığında toplandığı,

- Algıda, hileli bir işlemin büyük veya küçük tutarlarda olabileceği,

- İnsanın zihinsel algısında bir işlemin tam çıkması ile hileli gözükmesi arasında bir ilişki gördüğü,

- Hileli bir işlem yapılacağında hileli tutarın aynı miktara göre değil bir önceki ve bir sonraki tarihteki tutarlara göre bakılarak yapılacağı algısı tespit edilmiş̧tir.

\section{SONUÇ}

Hilede ana unsur insandır. İnsanın hileli işlemleri zihnindeki kurgulama biçimine ilişkin ipuçlarının yakalanması durumunda bu durumun denetimde kullanılabilecek bir aracı haline getirilmesi de mümkün olabilecektir. Bunun için insan zihninde mental hesaplamaların nasıl yapıldığı ve nasıl algıladığının bilinmesi gereklidir.

Yapılan bu araştırmada insan zihnindeki sayı üretiminin belli sistematik kurallara göre olup olmadığı sorgulanmıştır. Bunun için ondalık, yüzdelik ve farklı sayı aralıkları için rassal sayı üretilmesi istenmiş ve oluşturulan sayıların rassal olmadığı tespit edilmiştir. Bu durum insanların rassal sayı üretimi kendi zihinlerindeki mental hesaplama işlemi sonucundaki belli bir sistematik kurala göre gerçekleştirdiği varsayımını doğrulamaktadır. Bu nokta finansal tablolardaki yapılan hilelerinin tespit edilebilmesi açısından önemli bir konudur. İnsanın kendi bilişsel düzeyinde hileli bir işlem yapmak için ürettiği sayıları rassal olarak oluşturduğunu düşünse de gerçekte rassal olmadığının görülmesi, kullanılacak örüntülerle bu durumun tespiti ile hileli işlemlerin ortaya çıkartılması mümkün olabilecektir. Finansal tablolardaki tutarların rassal olarak oluşup oluşmadığının örüntülerle tanımlanacak bir algoritma ile belirlenmesi durumunda denetimdeki riskli noktaların belirlenmesinde faydalı bir araç haline gelebilecektir.

Örüntüleri tespitinde örüntülere etki eden birçok faktörün varlığı unutmamalıdır. Bu çalışmada sadece cinsiyet değişkeni kontrol altında tutulmuş, diğer değişkenlerin (yaş, eğitim, meslek, vb.) değişmediği varsayımı ile hareket edilmiştir. Bundan sonra yapılacak çalışmalarda hileli davranışlara ilişkin örüntülerden oluşturulacak bir modellin oluşturulması ile finansal tablolardaki hileli işlemlerin tespit edilebilmesi mümkün olabilecektir. Ancak söz 
konusu yöntemlerin sadece denetçiye denetim için yardımcı bir araç olduğu unutulmaması gereken önemli bir noktadır.

\section{KAYNAKLAR}

ACFE Report (2018), https://s3-us-west-2.amazonaws.com/acfepublic/2018-report-to-thenations.pdf (Erişim Tarihi: 16.04.2019)

Akkaş, M.E. (2007), "Denetimde Benford Kanunu'nun Uygulanması”, Gazi Üniversitesi İktisadi ve İdari Bilimler Fakültesi Dergisi 9(1), ss.191 - 206

Aktar, Y. (2016), “Türkiye' de Yasal Boşluk ve Esnekliklerden Yararlanılarak Gerçekleştirilen Yaratıc1 Muhasebe Uygulamaları", Vergi Dünyası Dergisi, Sayı 418, ss.45

Bozkurt, N. (2000), "Mali Tablolarda İşletme Yönetimi Tarafından Yapılan Hileleri”, Muhasebe ve Finansman Dergisi, Sayı 12, ss.15-22

Christensen, J.A.- Byington, J.R.- Blalock, T.J. (2005), "Sarbanes-Oxley: Will You Need A Forensic Accountant?”, Journal of Corporate Accounting Finance, 16(3), pp.69-74

Çatıkkaş, Ö. (2011), “İşletmelerde Mali Tablo Hileleri”, Denetişim, Sayı 8, ss.18-19

Erdem, Z. (2014), "Hile Denetimi ve İç Kontrol İlişkisi”, Yayınlanmamış Yüksek Lisans Tezi, ss.16

Ertekin, K. (2017), "Hile Denetimi: Kırmızı Bayrakların Tespiti İçin Kullanılan Proaktif Yaklaşımlar”, Muhasebe ve Finansman Dergisi, Sayı 75, pp.75-77

Marşap, B. - Gökten, P.O. (2016), "Davranışsal Muhasebe: Kuramsal Yaklaşım”, İşletme Araştırmaları Dergisi, 8(4), ss.354.

Terzi, S. - Şen, İ.K. (2015), “Adli Muhasebede Hilelerin Tespitinde Yapay Sinir Ağ1 Modelinin Kullanımı”, Uluslararası İktisadi ve İdari İncelemeler Dergisi, Sayı 14, ss.481

Türkyener, C. M. (2007), Benford Yasası ve Mali Denetimde Kullanımı, Sayıştay Dergisi, Say1 64, pp.111-121

Wolfe, D.T.- Hermanson D.R. (2004), "The Fraud Diamond: Considering the Four Elements of Fraud.",The CPA Journal, pp.38-41

Yıldız, E. - Başkan, T.D. (2014), "Muhasebe Hilelerinin Önlenmesinde Kullanılan Araçlar: BİST Şirketleri Üzerine Bir Araştırma”, Muhasebe ve Finansman Dergisi, Sayı 62, s.2 
